Article

\title{
Review of Partial Discharge Activity Considering Very-Low Frequency and Damped Applied Voltage
}

\author{
Mohamad Ghaffarian Niasar ${ }^{1, *}$, Xiaolei Wang ${ }^{2,3}$ and Respicius Clemence Kiiza 4 \\ 1 Department of Electrical Sustainable Energy, Delft University of Technology, 2628 CD Delft, The Netherlands \\ 2 Digital Grid Research Institute, China Southern Power Grid, Guangzhou 510663, China; xiwang@kth.se \\ 3 School of Automation, Guangdong University of Technology, Guangzhou 510006, China \\ 4 Dar es Salaam Institute of Technology, Dar es Salaam P.O. Box 2958, Tanzania; respic@kth.se or \\ respicious.clemence@dit.ac.tz \\ * Correspondence: M.GhaffarianNiasar@tudelft.nl
}

check for

updates

Citation: Niasar, M.G.; Wang, X.; Kiiza, R.C. Review of Partial Discharge Activity Considering Very-Low Frequency and Damped Applied Voltage. Energies 2021, 14, 440. https://doi.org/10.3390/ en14020440

Received: 23 December 2020

Accepted: 12 January 2021

Published: 15 January 2021

Publisher's Note: MDPI stays neutral with regard to jurisdictional claims in published maps and institutional affiliations.

Copyright: (C) 2021 by the authors Licensee MDPI, Basel, Switzerland. This article is an open access article distributed under the terms and conditions of the Creative Commons Attribution (CC BY) license (https:/ / creativecommons.org/licenses/by/ $4.0 /)$.

\begin{abstract}
When detecting the presence of partial discharge (PD) activity in the insulation system in high-voltage equipment, the excitation voltages at variable frequency have been widely used instead of power-frequency $(50 / 60 \mathrm{~Hz})$ sinusoidal voltage in order to reduce the charging power. This work reviews the relevant research on PD activity at very low frequency (VLF) method, including sinusoidal or cosine-rectangular voltage shape, and damped AC (DAC) method. Based on the research history and development status, some major PD characteristics, such as PD inception voltage (PDIV), PD amplitude, PD charge, PD phase-resolved pattern, and several hot issues, such as surface charge decay and statistical time lag, have been discussed. Moreover, the advantages, disadvantages, and applied conditions of two reviewed methods has been summarized. Finally, the prospects have been made on the main development trends of this research field in the future.
\end{abstract}

Keywords: partial discharge; very low frequency method; damped AC method

\section{Introduction}

Partial discharge activity has been normally recognized as a symptom of degradation and overstress in high-voltage electrical insulation system. It has been reported in many sources, e.g., in [1], that the presence of partial discharge (PD) can indicate not only the electrical stress, but also the mechanical, thermal, or ambient stresses. Thus PD measurement has been used for many years as a powerful tool to detect and interpret the signature of locally confined insulation defects. For instance, loss factor measurement was a good criterion for the quality of cable with oil-paper insulation, but it was too insensitive to locate individual cavities and defects in the solid insulation of polymeric cables. Therefore, it becomes extremely important to subject polymeric cables to PD measurements in order to avoid early breakdown caused by singular weak spots, which cannot be detected in loss factor measurements [1]. PD activity is normally measured with $50 / 60 \mathrm{~Hz}$ AC sinusoidal voltage stimulus in an on-site testing situation, but it can also be measured at other voltages or frequencies [2] and IEEE Std 400.3TM-2006 [3]. During the last decades a number of voltage excitations are introduced to detect electrical PD related defects in the shielded power cable systems, as shown in Table 1. 
Table 1. Different voltage excitations for partial discharge (PD) detection in shielded power cable systems.

\begin{tabular}{ccc}
\hline & Lab-Testing Voltages & On-Site Testing Voltages \\
\hline Continuous excitation & AC 20-300 Hz & $50 / 60 \mathrm{~Hz}$ AC \\
Temporarily excitation & AC Very Low Frequency (VLF 0.01 Hz to 1.0 Hz) & - \\
\hline
\end{tabular}

The intention of varying frequency methods is based on the fact that quality assessment of electrical equipment could be performed at other frequency other than power frequency, if the relevant results yielded from two compared frequencies are similar. On the other hand, in the case that the results are not similar, the information of frequencydependence of PD behavior can be obtained. In this case, the benefit of this method is that the local conditions at defects within or on the insulation, such as electric field distribution, surface charge accumulation and decay process, change with the varying frequency, leading to the changing of PD behavior. The PD frequency-dependence has been utilized in extracting more information about the condition of insulation system than that is possible from the traditional PD measurements at a single frequency. For instance, the nature of frequency-dependence of PD behavior could be useful for the classification of different PD defects and evaluation of the degree of progressive aging [4].

The primary aspect of using other frequencies than power frequency in high-voltage diagnostic field is to choose practical and economically realistic supply systems. Considering the cost, size, and weight of the energizing equipment, the simplest approach is to use appropriate supply frequencies. The power P needed to stress the insulation system is determined by the test frequency $f$, test voltage $U$ and capacitance of test object $C$

$$
P=2 \pi \cdot f \cdot C U^{2}
$$

The supply frequency needs to be reduced when the test object is prevailingly capacitive, such as high-voltage power cables, which require high capacitive power at powerfrequency AC stress condition. Thus, the developed method for reducing the capacitive charging power is to detect the presence of PD activity with very low frequency (VLF) method, like stressing the test object at $0.1 \mathrm{~Hz}$, or by using damped $\mathrm{AC}$ method in the range of 20-1000 Hz [5,6], which has been increasingly popular for the PD detection of high-voltage power cables [2]. On the other hand, the supply frequency is enhanced when the test object is prevailingly inductive [5]. For instance, transformer windings are often tested in the frequency range of $100-400 \mathrm{~Hz}$ to avoid core saturation at power frequency during the test $[7,8]$.

However, at the moment there is no review paper on the relevant works about PD behavior at variable frequency of excitation voltage. It is significantly important since variable-frequency PD behavior covers a great number of works in the research field of PD activity. The review paper can provide a clear picture about present research achievements and better guide the future work in the relative field. The paper therefore provides a full review of research on PD behavior at VLF method including sinusoidal or cosinerectangular voltage shape, and DAC method, since they have the same purpose of practical application in the field of insulation diagnosis. The research history, current development status, existing problems and present practical application of PD measurement for each method have been reviewed. Some major PD characteristics, including PD inception voltage (PDIV), PD amplitude, PD charge, and PD phase-resolved pattern have been discussed. Several hot issues, such as surface charge decay and statistical time lag, have been analyzed. Then, the advantages, disadvantages, and applied conditions of two reviewed methods has been summarized. Based on the current investigation, the prospects have been also made on the main development trends of this research field in the future. 


\section{VLF Method}

\subsection{Background}

One of the original works on the subject of high-voltage testing of electrical insulation with frequency lower than power frequency was given in 1961 by Bhimani [9]. Before this, DC voltage tests as a more convenient substitute for power frequency test were performed with the same motivation of reducing the power supply. However, although DC voltage has proved effective over many decades for diagnosing the impregnated paper insulation, the applied DC voltage must be several times higher than that for the case of an AC applied voltage due to the absence of polarity changing. On the other hand, the resulting space charging effect under the influence of DC voltage would cause the preliminary damage of the insulation for polymeric insulated cables at high and extra-high voltages. An illustration of space charge effect after DC testing cross-linked polyethylene cables (XLPE) cables is shown in Figure 1. These are the main reasons why DC voltage test cannot represent a usable method of detecting faults in insulation system [10]. Moreover, it has been found that testing with DC voltage does not stress the insulation in the same way as that with power frequency, because of the great difference in voltage distribution through heterogeneous (laminated) insulation system under DC stress compared to AC stress. For instance, different layers of machine insulation with different permittivities and conductivities happen to have frequency- dependent field distribution. The field distribution has been found to be dominated by the conductivity of insulation at DC voltage and at very low frequencies. At power frequency, however, the field distribution is determined by the permittivity of insulation.

voltage distribution

when voltage is applied

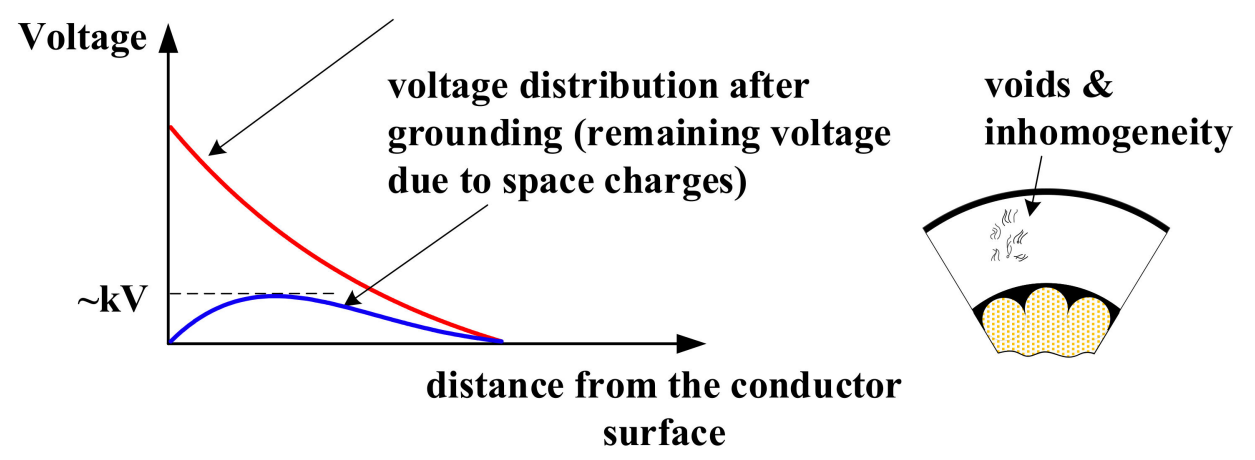

Figure 1. Space charges created in voids of polymeric cables during DC testing.

To choose the lowest possible frequency that would yield a field distribution $99.5 \%$ capacitive for the most common insulating materials, the compromise between DC and power frequency has been determined to be around $0.1 \mathrm{~Hz}$. Later, a two-layer heterogeneous dielectric system was studied by Virsberg and Kelen in 1964 [11]. The analysis indicated that the field distribution was still determined by the permittivity at $0.1 \mathrm{~Hz}$ if none of the volume resistivities of materials in the heterogeneous system was lower than $1011 \Omega \cdot \mathrm{m}$. The VLF test method was also early used on power cable insulation in 1968 by Haga and Yoneyama [12]. The breakdown strength of oil-impregnated paper cable was studied at various frequencies of applied voltage.

The interest of VLF method at the beginning was mainly to ensure that the insulation system could take this over voltage by performing overpotential testing [13-16]. Eager et al. found that the breakdown voltage of laboratory aged XLPE cable at $0.1 \mathrm{~Hz}$ was approximately similar to that at $60 \mathrm{~Hz}$. Testing at $0.1 \mathrm{~Hz}$ appeared to be a satisfactory alternate to DC testing method due to very little damage to the insulation [13]. However, later research results showed that the breakdown voltage of healthy insulation at $0.1 \mathrm{~Hz}$ 
was about twice of that at $50 \mathrm{~Hz}$ [15]. The results in [16] also found that the breakdown mechanisms at $0.1 \mathrm{~Hz}$ and at power frequency or adjacent frequencies were different.

According to IEEE Std 400.2TM-2004 [17], VLF testing method usually utilizes AC signals in the frequency range from $0.01 \mathrm{~Hz}$ to $1 \mathrm{~Hz}$ and the most commonly used VLF test frequency is $0.1 \mathrm{~Hz}$. The standard accepts four different voltage waveforms, including VLF cosine-rectangular (VLF CR) and sinusoidal waveform as the two most commonly used ones. The description and application of VLF CR voltage can be found in Section 2.5. VLF testing method can be used in both withstand and diagnostic tests. It has been well accepted for the insulation system of shielded power cables and AC electric machineries [17,18].

\subsection{PD Measurement}

Early research about PD measurements at VLF method mainly focused on whether the results obtained at low frequencies were similar compared with those at power frequency. Surface and void discharge measurements on polyethylene samples were already performed by Bhimani [9]. Later, Hilder tested PD characteristics on polyethylene samples with artificial voids. The results showed that PDIV at $0.03 \mathrm{~Hz}$ and $50 \mathrm{~Hz}$ were similar and the peak values of discharge magnitude were of the same order $[19,20]$. The similar results were also obtained by Reynolds that PDIV and discharge magnitude were similar at $0.1 \mathrm{~Hz}$ and $60 \mathrm{~Hz}$ [21]. As no suitable commercial generator was available at that time, Miller and Black developed a new type of low-frequency low-noise generator in 1977, which was used in their study of frequency-dependence of PD magnitude distributions [22,23]. The key findings were that for epoxy resin samples PDIV was virtually constant over the frequency range from $0.1 \mathrm{~Hz}$ to $50 \mathrm{~Hz}$; however, it would increase at low frequency when there was significant conduction across the void surfaces. PD pulses of smaller magnitude tended to occur at low frequency under normal ambient conditions. Some laboratory experiments on power cables and generators also indicated that PD characteristics detected at low test frequencies were approximately identical to that under power frequency source [24-26].

However, recent studies have showed the dissimilarity in PD characteristics at different test frequencies. Some results have confirmed that the varied frequency, falling to the millihertz range, can provide additional information about the insulation property. Low-frequency PD measurements have been covered much in the work at Royal Institute of Technology (KTH) [4,27-33]. Edin developed a measurement system for variablefrequency Phase Resolved PD Analysis (VF-PRPDA) with the voltage frequency range of $1 \mathrm{mHz}-400 \mathrm{~Hz}$ and also for the simultaneous measurement of VF-PRPDA and dielectric spectroscopy. PD measurements were performed on point-plane gaps and artificial cavities, but also on an insulated stator bar and a paper-insulated cable [4]. The measurement results showed that $P D$ activity in general was frequency dependent over the frequency range of $1 \mathrm{mHz}$ up to $400 \mathrm{~Hz}$. The main PD quantities, such as PDIV, PD magnitude and PD phase-resolved pattern, were observed to vary with test frequency. One example showing the significant difference of PD charge at low frequencies and power frequency can be seen in Figure 2 [29]. The results in [29] indicates that frequency-dependence of PD behavior is related to surface and bulk conducting mechanisms, frequency-dependent field distributions, and statistical effects of the supply of seed electrons. 


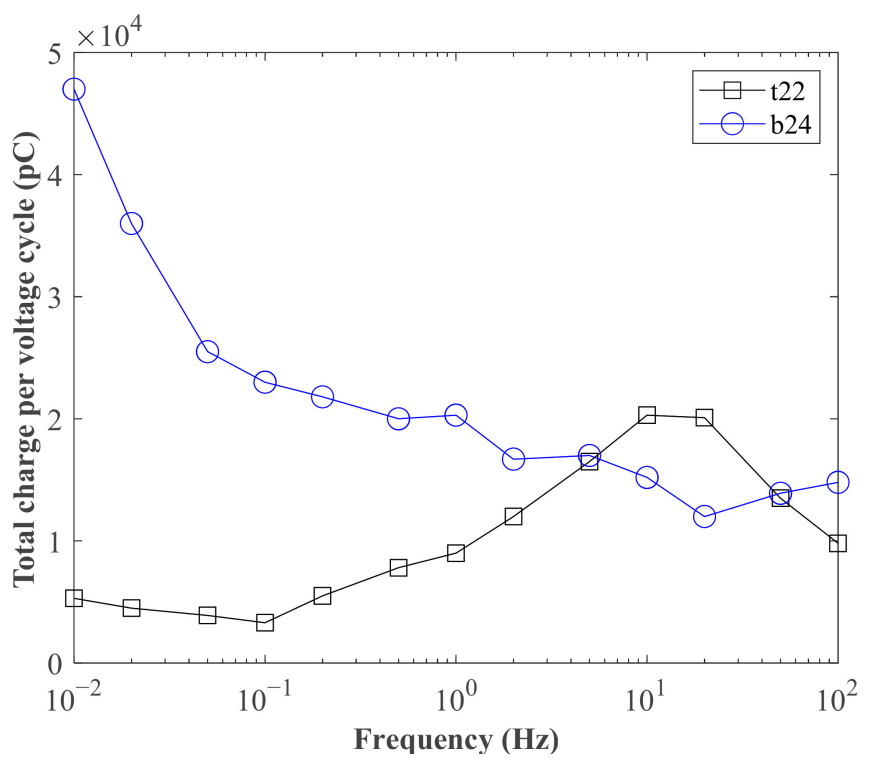

Figure 2. Total charge per voltage cycle of variable-frequency Phase Resolved PD Analysis (VFPRPDA) measurements on two aged stator bars (epoxy-mica insulation) from a hydro-power generator; $\mathrm{t} 22, \mathrm{~b} 24$ refer to Micapact insulation, where $\mathrm{t}$ means the half-coil from the top of the slot and $\mathrm{b}$ denotes it from the bottom of the slot. Reproduced from [29].

Later, Forssén continued the work and focused on the PD activity in disc-shaped cavities in polycarbonate at variable frequency range of $0.01-100 \mathrm{~Hz}$ [30-32]. The results showed that frequency-dependence of PD characteristics can change with the applied voltage amplitude, cavity location (insulated or electrode bounded), and cavity diameter. It was observed in [30] that at an applied voltage of $8 \mathrm{kV}$, the maximum PD magnitude at $0.01 \mathrm{~Hz}$ and $100 \mathrm{~Hz}$ is about $400 \mathrm{pC}$ and $900 \mathrm{pC}$, respectively. For the case of an applied voltage of $10 \mathrm{kV}$, PD magnitude is about the same at both frequencies, but the number of PD events per voltage cycle at $0.01 \mathrm{~Hz}$ is lower than that at $100 \mathrm{~Hz}$. This can be explained by the enhanced emission of electrons from the cavity surface with the increasing electric field. Thus the statistical time lag becomes shorter and its influence on the PD activity diminishes. Due to the disappearance of statistical effect, the surface charge decay in the cavity may lead to the dominating influence on the frequency-dependence of PD behavior. Considering the electrode bonded cavity [30], it can be seen that PD activity is almost extinguished due to the enhanced surface charge decay at low frequency. PD activity varies more with the changing of frequency in an electrode bounded cavity than that in an insulated cavity.

Considering the stator insulation of rotating machines, Taylor proposed the methods of measuring dielectric response and PD activity simultaneously at varied low frequency [33]. It was indicated that PD frequency-dependence had some promise for distinguishing PD sources: it seemed for example likely that delamination might be more readily distinguished from voids with varied frequency and this would be an important distinction to make.

There also exist a great number of works concerning frequency-dependence of PD behavior from many researchers worldwide. Surface discharge characteristics at low frequencies of $0.02 \mathrm{~Hz}, 0.1 \mathrm{~Hz}$ and power frequency test voltages have been compared in [34]. Zhou et al. investigated the influence of test frequency on corona discharge in the air [35]. The effect of temperature on corona discharge and aging on cavity discharge was studied at very low frequency of $0.1 \mathrm{~Hz}$ by Nguyen et al. [36-38]. Moreover, electrical tree growth associated with PD characteristics has been investigated at VLF voltage excitation [39]. Considering the industrial application aspect, the comparison of PD characteristics of power cable termination at test voltages with very low frequency $(0.1 \mathrm{~Hz})$ and at power frequency can be found in [40]. Nair et al. suggested that slot discharges in rotating machine 
insulation system could be identified by using low-frequency PD measurements based on the study of slot discharge pattern [41]. The online PD measurements and the offline VLF PD measurements on a 50-year-old hydrogenator stator in Norway were compared in [42], founding that both offline VLF and online PD detection could identify abnormal PD activity in a specific phase; although, the PD patterns were not similar for these two detection methods. Based on the existing research, the obtained frequency-dependence of PD characteristics can be found in Section 2.4.

Although VLF test voltages are far from stresses in service, PD measurements at variable low frequency have also attempted to apply on generator stator bars [29,43], oil-paper insulation of medium voltage cables [43], and $10 \mathrm{kV}$ extruded cables [44] in on-site testing situation. Later, Hauschild indicated that VLF voltages were well introduced not only for diagnostic tests but also for the quality acceptance tests on medium voltage cables (mainly due to low power demand and being compact). However, they were not recommended for the quality acceptance tests of extruded HV and EHV AC cables [45].

In addition to VLF PD measurement, VLF diagnostic test method also includes VLF dissipation factor (DF) measurement, VLF dielectric spectroscopy, VLF leakage current and so on [17]. For instance, it was proved in $[46,47]$ that the DF measurements using VLF sinusoidal waveform in aged cable system are sensitive to water tree degradation and insulation aging. David et al. investigated the aging of epoxy-mica insulated generator bars by low-frequency dielectric spectroscopy technique [48]. Loss currents in medium-voltage cable were measured at high voltages and frequencies from $0.1 \mathrm{mHz}$ to $1 \mathrm{kHz}$ by using a programmable high-voltage VLF generator given in [49]. In reality, field testing techniques frequently employ a combination of diagnostic and withstand test methods. Test standards, e.g., IEEE Std 400.2TM-2004 [17] recommend the test methods to be selected based on their ease of operation, operator training requirements, cost/benefit ratio, and the condition of insulation system.

\subsection{PD Measurement}

In order to describe the physical mechanism behind frequency-dependence of PD behavior, PD physical models in dielectric-bounded cavities have been described to compare with the experimental results at variable frequencies; some of the results even cover the frequencies above $50 \mathrm{~Hz}$ [5,6,31]. Parameters from the models can be identified to affect PD activity; for instance, conductivity of material, statistical time lag, and PD inception field [31]. Physical PD models mainly include equivalent circuit model, dipole model, Niemeyer's Model, and Finite Element Analysis (FEA) model. More details of each model are described as follows.

\subsubsection{Capacitive Equivalent Circuit Model}

In this model, discharge is represented by an instantaneous change with the changing of a capacitance in the test object. The classical capacitive PD model is illustrated with three capacitances, which represent the capacitance of bulk dielectric of test object between electrodes, the capacitance of healthy dielectric between cavity and electrodes, and the cavity. This model is also referred as "abc" model. More basis of equivalent circuit model has been interpreted in [50-52]. Gäfvert et al. studied PD frequency-dependence behavior based on a three-capacitance circuit model representing an isolated cavity within a dielectric material and the model could be used for the frequency even lower to $0.01 \mathrm{~Hz}$ [53]. The similar models have been used to study the stochastic process of PD behavior $[54,55]$. However, it seems that the basic abc model of insulation system with a single PD source is only appropriate for the frequencies greater than $10 \mathrm{~Hz}$ [43]. Actually, PD statistical behavior based on this three-capacitor circuit is very complex, even though the circuit is simple and deterministic. This model is therefore not realistic to describe the cavity property during the PD process.

The lumped capacitance model is the main equivalent circuit describing PD behavior, as described in [56-59]. Internal PDs in solid dielectric at variable applied frequencies were 
studied by a developed lumped circuit model given in [59], but the applied frequency was at $50 \mathrm{~Hz}$ or over. PD behavior at low frequency range has not been reported yet based on the lumped capacitance model.

\subsubsection{Dipole Model}

In the capacitive equivalent model, the apparent charge concept cannot reflect the real charge activity within the cavity. The electromagnetic transients detected at electrodes are not caused by discharging process of an imaginary cavity capacitance. Therefore, Pedersen et al. proposed the dipole model to study PD transient process [60,61]. Later, Lemke further confirmed that dipole model was a better approach to reflect the physics process of PD within a gaseous cavity [52]. In this model, the charge induced on the electrodes of test object is the result of a dipole moment established at the PD site. Figure 3 illustrates the dipole model for a case when the electrodes are disconnected from the HV supply during the transition time. The current $i_{c}(t)$ due to the moving charge carriers must be equal to the displacement current $i_{b}(t)$ through the solid dielectric between cavity and electrodes. This current is also equal to the current $i_{a}(t)$ through test-object capacitance $C_{a}$. As a consequence, $C_{a}$ is partially discharged, leading to a voltage step $\Delta V_{a}$. More detailed interpretation of dipole model can be found in [51].

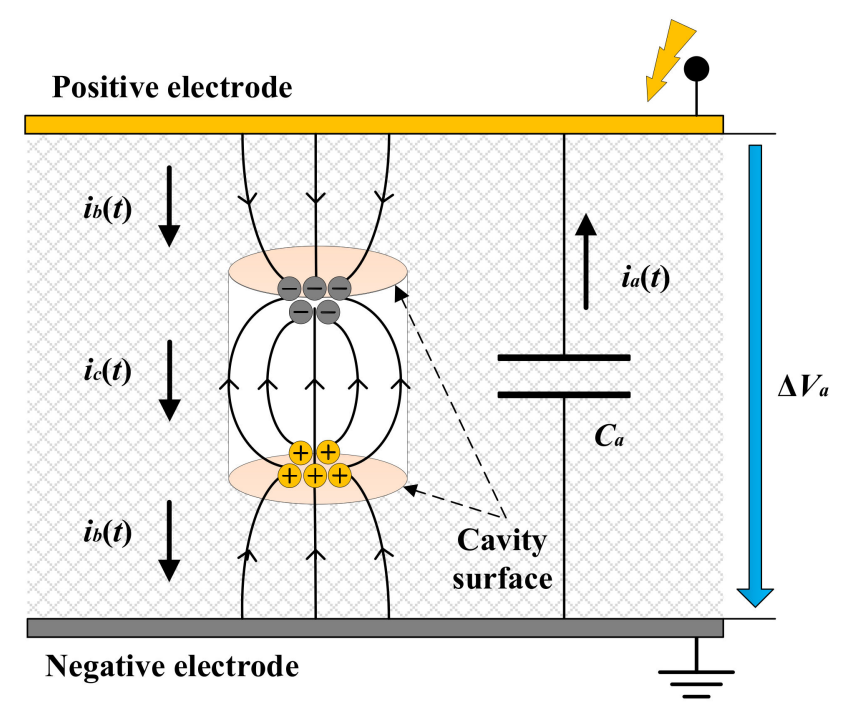

Figure 3. Dipole model to describe PD transient process.

PDIV changing with PD charge and cavity diameter has been calculated for an XLPE medium voltage cable by using dipole model, as described in [51]. The curves are satisfied compared with practical experience although the quantitative values are only approximations. However, PD behavior at low frequency range based on dipole model has not been studied yet.

\subsubsection{Niemeyer's Model}

A physical PD model that simulated streamer discharge phenomenon appearing in a dielectric-bounded spheroidal cavity was previously developed by Niemeyer in 1995 [62,63]. The model included, in detail, a mathematical model of initial electron generation, a model of streamer process, and it gave the analytical tools for the estimation of major PD quantities.

Based on the attempts to improve the work of Niemeyer, Bodega et al. proposed a numerical model to simulate the PD process in the frequency range from $0.1 \mathrm{~Hz}$ to $1000 \mathrm{~Hz}[6,64]$. PD behavior was theoretically analyzed at different applied frequencies and the theoretical approach was compared with the experimental results. Both detected PD magnitude and PD pattern demonstrated that PD process at very low frequency can 
be very close or quite different than that at $50 \mathrm{~Hz}$. The main reason for this particular behavior was that the decay time of deposited charges could change over several orders of magnitude depending on the condition of cavity surface. The interpretation was proposed based on the assumption that the time interval between two consecutive PD events was of the same order of magnitude as the period of AC stress; therefore, the following situations can be analyzed based on the charge decay time $\tau_{c d}$ compared with the duration of test voltage period $1 / f$. In the case of $\tau_{c d} \gg 1 / f$, the charges cannot decay between two consecutive PD events and strongly contribute to the cavity field, leading to the phase shifting of PD pattern and presence of PD pulses during the voltage zero crossing. In the case of $\tau_{c d} \ll 1 / f$, the deposited charges will not give a significant contribution to PD process and PD activity will be ignited in the absence of surface charge inside the cavity. An intermediate case that PD process occurs at $\tau_{c d} \approx 1 / f$, the charges deposited by PD events could contribute to the inception of next PD event. The Poissonian field contribution depends on the portion of charges deposited by the previous PD events and present in the cavity during the successive PDs. The decay time of deposited charges is strongly dependent on the conductivity of cavity surface based on the expression presented in [62].

$$
\tau_{c d}=\frac{\varepsilon_{0} \cdot D_{m}}{4 \cdot \sigma_{s}}
$$

where $D_{m}$ is the diameter of the cavity, $\varepsilon_{0}$ represents the permittivity of vacuum. It was also indicated that the charge decay time could be in the range of $10^{-3}-10^{3} \mathrm{~s}$ for cavities with a diameter of a few millimeters [62].

The similar model described by Cavallini and Montanari gave an insight to trapping and detrapping phenomena occurring on the cavity surface between PD consecutive events, and the model could be adapted for the frequency range from 0.1 to $300 \mathrm{~Hz}$ [5]. The behavior of PD quantities, such as PD pattern, maximum PD amplitude, PD height and phase distributions, varying with the function of test frequency was evaluated based on physical models and compared with the experimental results. It was assumed in [62] that detrapping from a negatively charged surface was innately much more difficult than detrapping from a positively charged surface, which results in the reduction of the availability of starting electrons. In [5], this effect was modeled by a reduction of the detrapping rate using a suitable constant.

\subsubsection{Finite Element Analysis (FEA) Model}

The field-based PD models have been established based on the Finite Element Analysis (FEA) method. The advantage of this model is that discharge events can be simulated dynamically while the electric field inside the cavity can be calculated numerically. Forssén proposed a charge consistent model to simulate the sequence of PD pulses in a cylindrical cavity inside the insulation material at variable applied frequency from $0.01 \mathrm{~Hz}$ to $100 \mathrm{~Hz}[31,32,65,66]$. The spherical shape electrodes were used in the model geometry to concentrate the discharge to cavity center. The discharge was modeled dynamically by means of increasing the conductivity of a cylinder centered inside the cavity. The conductivity of cavity surface was dependent on the amount of charges present on the cavity surface. It is correlated to the decay behavior of surface charge in the model. The simulation results showed that surface conductivity and surface emission of electrons of the cavity surface were changing with the varied test frequency. The simulation results of phase-resolved PD patterns in [31] were in general agreement with the experimental data but with a slightly difference. Moreover, based on Forssén's model, some improved models have also been developed to study frequency-dependence of PD behavior [67-69].

The models mentioned above were developed in a cylindrical cavity to simplify the computer simulation due to its symmetrical property. In reality, however, the most common types of cavity existing in the insulation material are either spherical or ellipsoidal; thus, the physical models representing PD behavior of a spherical cavity within the homogeneous dielectric material have been developed by Illias et al., and a lot of simulation works have 
been done to study the influence of frequency and amplitude of test voltage, cavity size and location, material temperature, and surface charge distribution on the sequence of PD events [70,71]. The model proposed in [70] studied the effect of different amplitudes and frequencies of test voltage on PD process, with the frequency range of $1 \mathrm{~Hz}$ up to $50 \mathrm{~Hz}$. Comparisons between PD measurement and simulation results of $\varphi-q-n$ plot also reveal a good agreement. In this model, the effect of charge decay because of surface conduction was modelled by means of a field-dependent surface conductivity inside cavity. The simulations indicated that certain parameters obtained from FEM model were greatly dependent on the applied voltage. Those parameters that are clearly affected by frequency-dependence of PD behavior can be readily identified, including electron detrapping time constant, surface conductivity of the cavity, initial electron generation rate, inception voltage, and extinction voltage.

\subsection{Frequency-Dependence of PD Characteristics}

Although significant numbers of researches concerning PD behavior and mechanism at VLF voltage have been done both in experiments and simulations, there exist some consistencies or inconsistencies in frequency-dependent PD characteristics between different studies. Some conventional parameters to describe PD signal are described as follows:

(a) PDIV. Most of the results show that PDIV increases with the decrease of test frequency, for instance, corona discharge in air studied by Zhou et al. [35], PD activity in discshaped cavities in polycarbonate insulation given in [32] and PD in XLPE cables with and without artificial internal defects in [72]. This slight increase can be explained by the influence of statistical time lag, as discussed in [32]. Moreover, Forssén et al. [30] have shown that PDIV depends mainly on the supply voltage magnitude and void size. However, a few works show that PDIV might be lower at VLF than that at power frequency, supported by the PD measurements in cavities in XLPE cable [34,73] and cable terminations [40]. It was reported in [74] that PDIV may also had a non-monotone behavior with the changing of test frequency. The effect of ambient conditions on PDIV was studied in [36] and the results showed that there was no change of PDIV at different temperatures at both $0.1 \mathrm{~Hz}$ and $50 \mathrm{~Hz}$ voltage excitations.

(b) PD magnitude. One general consensus from most works is that minimum PD magnitude remains roughly constant and is independent of the influence of variable frequency $[6,30,31]$. However, maximum PD magnitude either decreases $[30,31,40,69,70]$ or increases $[5,74]$ with the decrease of frequency. Bodega et al. reported that PD magnitude at VLF was either smaller or similar compared with that at $50 \mathrm{~Hz}$. There was a threshold frequency beyond which the discharge magnitude decreased with the increase of frequency $[6,64]$. Forssén and Edin concluded that average PD magnitude decreased with the decrease of frequency but only for the voltage magnitude slightly above the PDIV. For the higher voltages, PD magnitude was independent of test frequency. The dependency of PD magnitude on test frequency was greatly influenced by cavity size [30]. Zhou et al. found that with the decrease of test frequency, the maximum PD magnitude of corona discharge decreased in the positive cycle, but it slightly decreased and then increased in the negative cycle. The increase trend was more obvious for the higher voltages. The average PD magnitude almost followed the same trend with the varying of frequency [35].

(c) Phase-resolved PD pattern. This parameter has significant disagreements depending on the effect of variable frequency. PD Patterns might show essentially invariant compared with the test voltage of VLF and power frequency $[6,40,64]$. However, Forssén and Edin concluded that PD pattern would significantly change with the test frequency without specifying the variation trend [6,30]. Zhou et al. found that PD patterns distributed wider in positive corona discharge with the decrease of frequency [35]. PD tests involving surface discharges on polyethylene specimens were studied in [74]. It was shown that only frequencies larger than $300 \mathrm{~Hz}$ could cause significant change in PD pattern. In the case of PD activity occurred in embedded 
cavities; however, it was observed that the PD pattern was more sensitive to the frequency of the power supply. Statistical operators such as kurtosis and skew of mean pulse height and pulse count of PD patterns decreased with the increase of frequency, as studied in [34].

(d) PD charge. It was obtained in [70] that total charge magnitude per cycle decreased with the decrease of frequency, but mean charge magnitude increased. Forssén obtained the same variation trend for the total PD charge per cycle [32]. However, Hans reported that total charge per cycle was independent of frequency, but mean charge increased with the increase of frequency [4].

There are also other conventional PD parameters, such as PD repetition rate, PD extinction voltage, and pulse shape, showing agreement or inconsistencies on frequencydependent PD behavior. Therefore, intensive works need to be performed to understand the behavior of PD over a range of different test voltage frequencies for the same defect type and material. It is better to establish a common rule, but generally long time would be required to achieve an accurate description of PD phenomena. Moreover, it should be noted that the choice of power supply with VLF method is generally decided by economic consideration, rather than by physical analysis. The existing researches focus more on the physical mechanism of frequency-dependence of PD characteristics other than on industrial application, and the reliable diagnostic method of PD activity under low-frequency voltage excitation is still lacking. Thus it should make more practical application of VLF method on PD measurement in the future.

\subsection{VLF Cosine Rectangular Voltage}

The above review for VLF method refers to sinusoidal voltage excitations. In reality VLF method used for withstand test accompanied with PD diagnosis also includes VLF cosine-rectangular (VLF CR) voltage waveform. It is the first available VLF technology and still is the most common two standard VLF methods. Figure 4 illustrates the VLF CR voltage waveform at $0.1 \mathrm{~Hz}$ [75]. The polarity reversal of VLF CR voltage is cosine shaped with a frequency close to $50 \mathrm{~Hz}$, thus the field stress is comparable to the operating frequency.

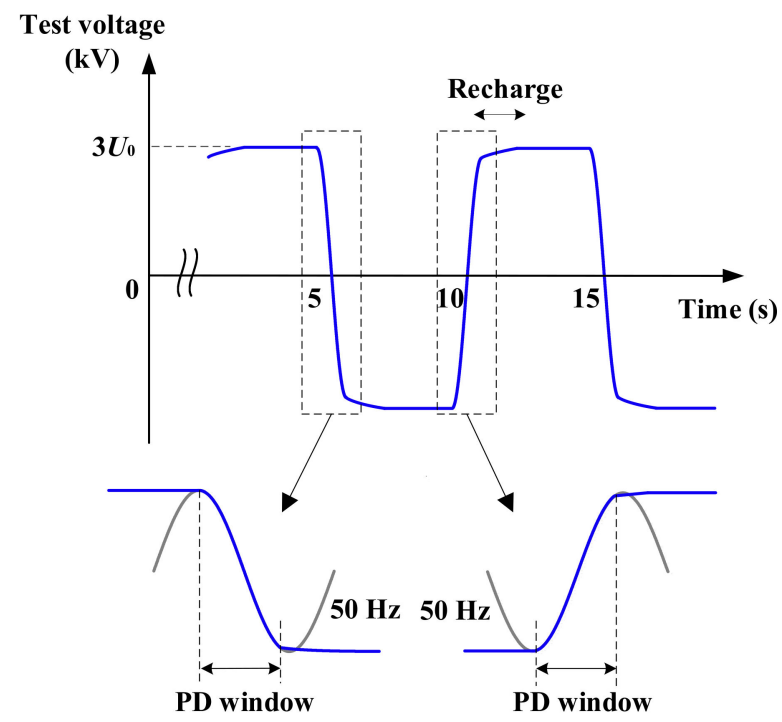

Figure 4. VLF cosine-rectangular voltage waveform.

Early research was performed in [76], which studied the PD activity by varying two parameters in VLF CR voltage waveform: the fundamental frequency and time function of the change of voltage polarity. Recently, several PD measurements by using VLF CR technique have been reported in [75,77-81]. It was observed in [77] that most of the PD events occurred at the transition zone at the period of voltage polarity changing. This could be useful in the detection of hidden defects existed in power cable. Thus this voltage 
waveform can be recommended to be used in the start of cable diagnostic process. PD diagnostics at different voltage waveforms and frequencies in [75] showed that in several field case studies PD diagnosis measured at VLF CR voltage was comparable to that at damped AC voltage for MV cable systems. The study in [79] further confirmed that although VLF-CR waveform resulted in higher PDIV and lower discharge magnitude, there was no obvious difference on the capability of detecting defects in the insulation systems between DAC and VLF CR voltages.

\section{DAC Method}

\subsection{Background}

Sinusoidal DAC voltage testing, also known as oscillating voltage wave (OVW) testing, was introduced in the late 1980s as an alternate to DC testing voltage [82-86]. Originally, DAC voltage could be in the form of oscillating switching impulse (OSI), with a higher test frequency of $1 \mathrm{kHz}-10 \mathrm{kHz}$, and it was introduced as a withstand voltage test for high-voltage XLPE-insulated cables for commissioning purpose $[85,86]$. This form is different from DAC voltage, which is used for non-destructive PD diagnosis and has the oscillating frequency typically ranging from $20 \mathrm{~Hz}$ to $500 \mathrm{~Hz}$ [87]. The voltage waveform and frequency of DAC method is in accordance with the recommendations of IEC 60270 [88]. Moreover, the stress inside the insulation system caused by DAC voltage is similar to that at power frequency $\mathrm{AC}$ excitation and the insulation would not be damaged due to the short duration of DAC voltage testing.

Early research on the exploration in the equivalence of DAC voltage waveform and the development of damped oscillating wave generator was given in [89]. The breakdown properties of samples modelling various defects in XLPE cable were studied with different voltage excitations. The results indicated that the detection of defects in insulation system by using OSW or VLF voltage required a lower voltage than that with DC. By combining these two voltage waveforms, detection capability would be further enhanced.

At present, there exist two commercially available systems which can generate DAC voltage. One system called Complex Discharge Analysis (CDA) was described in [90,91]. PD characteristics, polarization factor, and capacity of insulation can be determined under such voltage stress [91]. Based on this measuring system, Brettschneider et al. performed PD detection on two different types of cables: paper-insulated lead cables (PILC) and XLPE cables [92]. The results provided several examples of threshold values for PD assessment based on practical field experiences. The use of DAC voltage revealed high sensitivity for PD detention and recognition of electrical treeing.

Later, the system referred as Oscillating Waveform Test System (OWTS) was mainly established by E. Gulski, J. J. Smit, et al. at Delft University of Technology (TU delft) [93-95]. It has been widely used and most of detection results are obtained based on this system. To generate a DAC voltage waveform, as shown in Figure 5, the cable is charged with a DC steady state electric field over a period of just a few seconds, which has little effect on the property of insulation system. After charging-up stage, the cable is switched in series with an external air-core inductor. Thus, an oscillating voltage wave is used as an excitation voltage for PD detection. The schematic diagram of OWTS measuring circuit for PD detection and location in power cable is shown in Figure 6. 


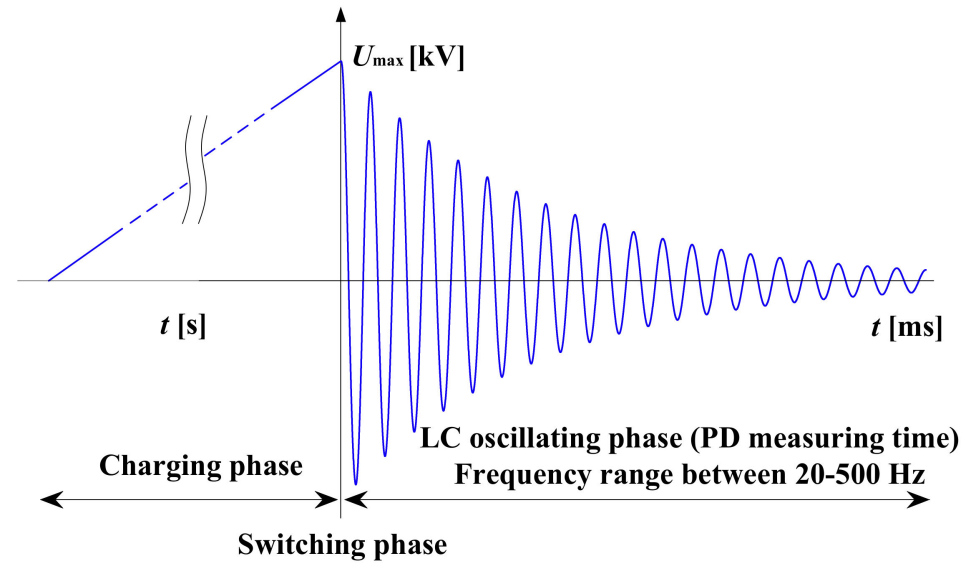

Figure 5. Schematic view of damped AC (DAC) excitation.

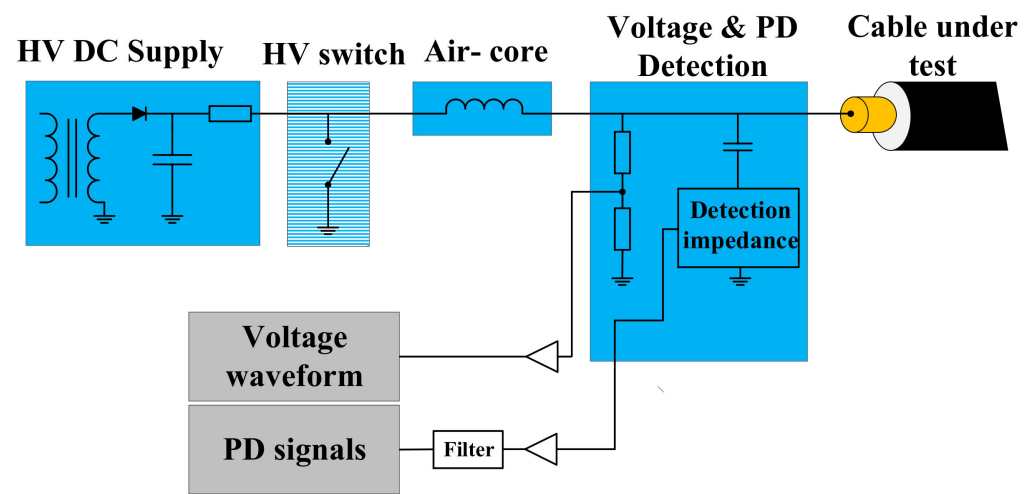

Figure 6. Schematic diagram of Oscillating Waveform Test System (OWTS) diagnostic tool.

The applications of DAC method are mostly based on the combination of voltage withstand test and advanced diagnostic tests, such as PD and DF measurements, known as monitored testing. The on-site monitored testing procedures for power cables have been summarized in [96]. It can be obtained that the monitored DAC testing can be used not only for diagnosis and condition assessment of service-aged cable systems, but also for after-laying testing of newly installed cable systems, as well as maintenance testing of repaired cables. DF value of insulation material can be estimated by using the decay characteristics of DAC voltage waveform [97-99]. The detailed theoretical method has been described by Houtepen et al. [99]. It has also been found that DF measurements are especially useful for detecting insulation aging in paper-oil insulated cables, with the indicator of DF value normally over $0.1 \%$, while the DF value is usually below $0.1 \%$ in new and in-service XLPE cables.

DAC method for onsite testing with PD measurements and DF estimation has been commonly employed for condition assessment of all types of power cable systems in several countries [92,95,100-102]. Attempts with DAC method have also been applied on generator stator insulation based on laboratory study [103-105], as well as on high voltage power capacitors for on-site PD diagnosis [106]. The achievements with DAC voltage described below are mainly based on power cable systems.

\subsection{DAC Test Parameters and Procedures}

According to IEEE Std 400.4 ${ }^{\mathrm{TM}}-2015$ [87], five test parameters of waveform should be considered for DAC voltage testing, they are (a) maximum DAC test voltage level VT [kVpeak]; (b) number of DAC excitations to be applied at selected DAC voltage levels during the test; (c) DAC frequency; (d) DAC damping percentage; and (e) DAC charging time in seconds. For all types of tests with DAC voltage, the maximum applied voltage 
and the number of DAC excitations should be selected to make in accordance with the purpose of test.

DAC voltage may consist of two phases. Firstly, in the DAC voltage step phase, voltage is increased to a selected maximum test voltage in selected steps, with a selected number of DAC excitations. Secondly, at the DAC voltage hold phase, a selected maximum DAC test voltage level is applied to the test object with a number of DAC excitations. In DAC monitored testing, PD detection can be performed during voltage step and hold phases. The duration of charging time greatly depends on the cable capacitance; that is the length of cable. It may vary much for different length of cable. Hauschild indicated that the charging time played a minor role in PD measurements with DAC voltage excitation, but it became more important in withstand test [45].

The voltage start oscillating with the resonant frequency $f$ of the circuit as [95]

$$
f=\frac{1}{2 \pi \sqrt{L C}}
$$

where $L$ is the fixed inductance of air core and $C$ is the capacitance of test sample.

\subsection{PD Measurements}

PD measurements on particular power cables with DAC voltage excitation have been performed much at TU delft based on both laboratory and on-site tests [93-100,107-110]. In general, one or more PD detection units can be connected to at least one of the cable terminations or cable joints. A proper triggering or synchronization between DAC voltage source and PD detection unit is needed, since DAC testing is not continuous but based on voltage excitations as applied to the power cable [87].

PD evaluation method has been well described in [95], mainly including: (a) PD signals from several DAC voltage waveforms can be used to localize PD sites in the power cable; (b) the values of capacitance $C$ and $\tan \delta$ can be calculated based on the characteristics of wave time and frequency of DAC voltage; and (c) the obtained PRPD pattern can be used for recognition purpose for insulation system. Later, Wester et al. further investigated the effect of testing frequency of DAC voltage for dielectric-bounded cavities and inception delay time of PD activity was discussed in details [108]. It was found that in the case of a lower applied voltage, the number of DAC excitation should be increased to obtain a stable PD inception due to a rather long delay time at lower applied voltage. It was determined by the decay factor rather than the testing frequency of DAC voltage. Considering AC and DAC voltages, the influence of the effect of voltage waveform and test frequency could be negligible in practice.

In order to confirm the harmlessness of DAC application on the insulation system from the viewpoint of PD characteristics, Takahashi et al. investigated the impact of repetitive application of DAC on the insulation performance of water tree aged XLPE cable [111,112]. The maximum PD charge was used to indicate the extent of damage of insulation system by applying PD inception tests and repetitive application tests. The results concluded that at repetitive DAC application the additional degradation to the water tree degraded XLPE cable could be very small and cable might have good self-recovering property.

Some investigations concerning DAC voltage have been done in some other works with regard to PD characteristics, insulation diagnosis, as well as technique improvement. A $20 \mathrm{kV}$ DAC voltage generator was developed by using novel high-voltage switch and it had been successfully applied in PD test and PD location test for a cable sample, as given in [113]. Three-dimensional statistical map has been made to investigate PD behavior in three artificial defects of cable joints at DAC voltage in [114]. The distinguish differences in three-dimensional maps of three defects may be helpful for the further study of pattern recognition. By using DAC, the successful application cases of multi-source defect diagnosis were introduced in [115]. Three concentrated PD defects in the middle joint position of a cable was discovered. In [116] by studying five different kinds of defect models, it 
was shown that DAC was successful in detecting serious defects in cable terminations and joints.

\subsection{PD Characteristics at DAC Voltage}

DAC testing method is based on single voltage excitation, and the following PD characteristics can be obtained from the PD activity at DAC voltage: (a) maximum PD amplitude; (b) phase-related PD pattern; (c) PD changes as a function of the decaying voltage; and (d) PD extinction voltage (PDEV) [87]. The principles to estimate the PDIV and PDEV during DAC testing voltage are explained in [100]. The PDIV voltage level of DAC excitation at which the first PD event has been observed.

Attempts to convince that DAC voltage with an oscillation of some hundreds of $\mathrm{Hz}$ can give the similar PD behavior as continuous AC voltage of power frequency, as discussed for power cables in [95,100,108,116], and also for rotating machines in [104]. By applying continuous AC and DAC voltages with the increased frequencies on samples with oil-related defect and samples of polymeric cable, the comparisons showed no major differences for PD characteristics, such as PDIV, PD magnitude, and phase-resolved PD patterns under two applied voltage waveforms. However, these cases are selected to demonstrate that PD activity behaves as frequency independent. A deeper look at the details in those results shows that they are not frequency independent either. It can be found in [93] that both PDIV and PD level at DAC voltage were much higher compared with those at $50 \mathrm{~Hz}$ energizing condition. Moreover, the frequency of DAC voltage waveform had no effect on the PDIV, but greatly influenced the measurable PD level. More measurable PD level could be obtained at lower frequency of DAC voltage. Morshuis et al. observed that PD magnitude measured with DAC voltage at frequency above $200 \mathrm{~Hz}$ was slightly lower than that at power frequency AC stress [117]. This is due to the sufficient availability of starting electrons after one PD event. The similar results can also be found in [100]. With regard to phase-resolved PD patterns, those obtained at DAC voltage excitation could provide the recognition of $\mathrm{PD}$ defects in different insulation systems.

Therefore, DAC voltage has been more and more widely used for non-destructive PD detection and location of power cables due to its convenient transportation and good test results in recent years. However, it has mentioned in [45] that DAC method cannot fulfil the major requirements of a test voltage for quality-acceptance tests of HV and EHV cables mainly due to its waveform which is far from the actual in-service voltage stress. Nevertheless, it is still considered as a voltage waveform for diagnostic tests. However, in reality, the frequency of DAC voltage could vary due to the different length of detected cable, leading to the changing of PD behavior caused by the defects in the cable insulation system. So the effect of frequency of DAC voltage on the PD characteristics and the related discharge physics need to be further investigated.

\section{Comparisons of VLF and DAC Methods}

Generally, VLF and DAC methods both have been widely used for PD detection in insulation system. Since DAC test normally lasts for a short time, typically $0.5 \mathrm{~s}$, it is considered less destructive than VLF test; thus, DAC testing could be used as the first step for the defect detection of insulation system in many cases [118]. Laboratory and field tests have shown that DAC and VLF voltage tests have different sensitivities in detecting different kinds of defects in the extruded MV voltage cable systems, as presented in $[15,89]$ : DAC voltage is more sensitive in detecting defects that cause void discharge type breakdown, while VLF is more sensitive in detecting defects that cause breakdown directly by inception of electrical tress. These two test voltage waveforms are in a complementary relationship with respect to defect detection capability. OSW or VLF can detect specific types of defects and the defect detection ability can be improved by combining both waveforms [117].

As a whole, VLF and DAC excitation voltages have some similar advantages, for instance, testing equipment is readily transportable with regard to weight and size; PD test 
can be stopped if desired; PDIV and PDEV can be measured for both voltage excitations; and the location of PD event can be detected. Considering individual test method, the main advantages and disadvantages of two methods for PD measurements are summarized in Table 2.

Table 2. Main advantages and disadvantages of VLF and DAC methods for PD measurements.

\begin{tabular}{|c|c|c|c|}
\hline $\begin{array}{l}\text { Voltage Source } \\
\text { Type }\end{array}$ & Advantages & Disadvantages & Applied Conditions \\
\hline $\begin{array}{l}\text { AC VLF method } \\
(0.01 \mathrm{~Hz} \text { to } 1.0 \mathrm{~Hz})\end{array}$ & $\begin{array}{l}\text { 1. PD frequency-dependent } \\
\text { behavior can be obtained at } \\
\text { frequency range of } \\
0.01-1 \mathrm{~Hz} \text {. } \\
\text { 2. Insulation condition can be } \\
\text { graded by comparing with } \\
\text { the previously accumulated } \\
\text { data. }\end{array}$ & $\begin{array}{l}\text { 1. PD characteristics obtained at } \\
\text { VLF voltage may not be } \\
\text { comparable with those obtained } \\
\text { at power frequency tests. } \\
\text { 2. PD detection time needs to be } \\
\text { increased as the frequency } \\
\text { decreases. } \\
\text { 3. PD detection with VLF }(0.1 \mathrm{~Hz}) \\
\text { AC excitation may have } \\
\text { limitation in some practical } \\
\text { conditions, such as for } \\
\text { evaluating water tree } \\
\text { contaminated insulation. }\end{array}$ & $\begin{array}{l}\text { 1. VLF voltage tests are well } \\
\text { accepted for withstand tests } \\
\text { and diagnostic tests. } \\
\text { 2. For cables, VLF test can be used } \\
\text { to test extruded, laminated, and } \\
\text { mixed dielectrics. The best } \\
\text { application is when eliminating } \\
\text { a few defects from good } \\
\text { insulation. } \\
\text { 3. VLF method can also be applied } \\
\text { on the acceptance testing and } \\
\text { routine maintenance testing for } \\
\text { AC electric machines. }\end{array}$ \\
\hline $\begin{array}{c}\text { DAC method } \\
(20 \mathrm{~Hz} \text { to } 500 \mathrm{~Hz})\end{array}$ & $\begin{array}{l}\text { 1. PD characteristics obtained } \\
\text { at DAC voltage are } \\
\text { generally comparable to } \\
\text { those at power frequency } \\
\text { voltage stress. } \\
\text { 2. PD patterns can show } \\
\text { additional information of } \\
\text { PD behavior as a function of } \\
\text { the decaying voltages. }\end{array}$ & 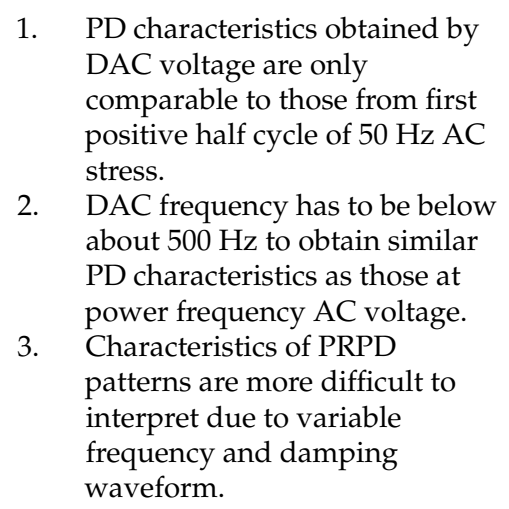 & $\begin{array}{l}\text { 1. The applications of DAC } \\
\text { method are mostly based on the } \\
\text { combination of voltage } \\
\text { withstand test and advanced } \\
\text { diagnostic tests, known as } \\
\text { monitored testing. } \\
\text { 2. Monitored DAC testing can be } \\
\text { widely applied on the diagnosis } \\
\text { tests of service-aged cables, } \\
\text { acceptance test of newly } \\
\text { installed cables, maintenance } \\
\text { tests of repaired cables. }\end{array}$ \\
\hline
\end{tabular}

\section{Conclusions}

A full review of research on PD activity at two variable-frequency AC stress, including very low frequency voltage and damped $\mathrm{AC}$ voltage, has been provided in this work. The research history and current development status, including PD characteristics, physical process, and practical application of each voltage excitation, have been reviewed. Then the advantages, disadvantages, and applied conditions of two reviewed methods has been summarized.

In general, VLF and DAC methods are normally widely used in voltage withstand tests and advanced diagnostic tests mainly for power cable systems, as well as for rotating machines. The already achieved results provide a clear picture about PD behavior and its physical mechanisms, as well as practical applications at VLF and DAC voltage waveforms. Considering the existing knowledge and information for practical engineers in the field of PD measurements and high-voltage insulation systems, the practical application of VLF method has been limited, compared with the physical analysis of PD activity at VLF voltage. It can be suggested that more results from practical applications have to be collected and used to fine tune, verify, and possibly further develop the physical models. On the other hand, with regard to DAC voltage, physical models should attempt to be expanded and validated for the application of DAC voltage. PD physical mechanism affected by DAC voltage needs to be further investigated. Moreover, more defects should be studied using DAC method to obtain all relevant PD patterns for defect identification. Knowledge rules 
for the purposes of condition assessment for insulation system should be further developed based on the PD results obtained with DAC method.

Author Contributions: Methodology, investigation, supervision, visualization, writing-review and editing, M.G.N.; reference collection, writing—original draft preparation, X.W.; supervision, writing - review and editing, R.C.K. All authors have read and agreed to the published version of the manuscript.

Funding: This research was funded by Natural Science Foundation of Guangdong Province, grant number 2017A030310272.

Institutional Review Board Statement: Not applicable.

Informed Consent Statement: Not applicable.

Data Availability Statement: No new data were created or analyzed in this study. Data sharing is not applicable to this article.

Conflicts of Interest: The authors declare no conflict of interest.

\section{References}

1. König, D.; Rao, Y.N. Partial Discharge in Electrical Power Apparatus; VDE-Verlag: Berlin, Offenbach, Germany, 1993.

2. IEEE. Guide for Field Testing and Evaluation of the Insulation of Shielded Power Cable Systems Rated $5 \mathrm{kV}$ and Above; IEEE Std 400TM-2012; IEEE: New York, NY, USA, 2012.

3. IEEE. IEEE. Guide for Partial Discharge Testing of Shielded Power Cable Systems in a Field Environment; IEEE Std 400.3TM-2006; IEEE: New York, NY, USA, 2007.

4. Edin, H. Partial Discharge Studied with Variable Frequency of the Applied Voltage. Ph.D. Thesis, Royal Institute of Technology, Stockholm, Sweden, 2001.

5. Cavallini, A.; Montanari, G.C. Effect of supply voltage frequency on testing of insulation system. IEEE Trans. Dielectr. Electr. Insul. 2006, 13, 111-121. [CrossRef]

6. Bodega, R.; Morshuis, P.H.F.; Lazzaroni, M.; Wester, FJ. PD recurrence in cavities at different energizing methods. IEEE Trans. Dielectr. Electr. Insul. 2004, 53, 251-258. [CrossRef]

7. Power Transformers-Part 3: Insulation Levels, Dielectric Tests and External Clearances in Air; IEC 60076-3; IDT: Geneva, Switzerland, 2013.

8. Peter, G.; Sherine, A. Induced over voltage test on transformers using enhanced Z-source inverter based circuit. J. Electr. Eng. 2017, 68, 378-383. [CrossRef]

9. Bhimani, B.V. Very-low-frequency high-potential testing. IEEE Trans. Power Appar. Syst. 1961, 80, 148-155. [CrossRef]

10. Peschke, E.; von Olshausen, R. Cable Systems for High and Extra-High Voltage: Cable Design and Accessories-Dimensioning, Development and Testing; Publicis MCD Verlg: Erlangen, Munich, Germany, 1999.

11. Virsberg, L.G.; Kelen, A. Some observations on the very-low-frequency testing of high-voltage machine insulation. In Proceedings of the International Council on Large Electric Systems (CIGRE), Paris, France, June 1964; Volume 2, Paper 108. pp. 1-19.

12. Haga, K.; Yoneyama, M. Breakdown strength and dielectric characteristics of oil-impregnated paper cable insulation at very-low frequencies. Electr. Eng. Jpn. 1968, 88, 39-48.

13. Eager, G.S.; Katz, C.; Fryszczyn, B.; Densley, J.; Bernsteln, B.S. High voltage VLF testing of power cables. IEEE Trans. Power Deliv. 1997, 12, 565-570. [CrossRef]

14. Gnerlich, H.R. Field testing of HV power cables: Understanding VLF testing. IEEE Electr. Insul. Mag. 1995, 11, 13-16. [CrossRef]

15. Oyegoke, B.; Hyvonen, P.; Aro, M.; Gao, N.; Danikas, M. Selectivity of damped AC (DAC) and VLF voltages in after-laying tests of extruded MV cable systems. IEEE Trans. Dielectr. Electr. Insul. 2003, 10, 874-882. [CrossRef]

16. Gockenbach, E.; Hauschild, W. The selection of the frequency range for high-voltage on-site testing of extruded insulation cable systems. IEEE Electr. Insul. Mag. 2000, 16, 11-16. [CrossRef]

17. IEEE. Guide for Field Testing of Shielded Power Cable Systems Using Very Low Frequency (VLF); IEEE Std 400.2TM-2004; IEEE: New York, NY, USA, 2005.

18. IEEE. Recommended Practice for Insulation Testing of AC Electric Machinery with High Voltage at Very Low Frequency; IEEE Std 433TM-2009; IEEE: New York, NY, USA, 24 February 2010.

19. Hilder, D.A.; Gray, V.N.; Black, I.A. The application of ramp and low frequency A. C. voltages to discharge detection. In Conference on diagnostic testing of high voltage power apparatus in service; IEE: London, UK, 1973; Volume 94, pp. 14-19.

20. Hilder, D.A. Partial Discharge Characteristics at Low-Frequencies. Ph.D. Thesis, Brighton Polytechnic, Brighton, UK, 1974.

21. Reynolds, P.H. Insulation evaluation techniques at very-low-frequencies. In Proceedings of the British Electrotechnical and Allied Manufacturers Associations-BEAMA Conference, Brighton, UK, May 1974; pp. 261-270.

22. Miller, R.; Black, I.A. Partial discharge measurements over the frequency range $0.1 \mathrm{~Hz}$ to $50 \mathrm{~Hz}$. IEEE Trans. Electr. Insul. 1977, EI-12, 224-233. [CrossRef] 
23. Miller, R.; Black, I.A. Partial discharge energy measurements on electrical machine insulation when energized at frequencies between $0.1 \mathrm{~Hz}$ and power frequency. IEEE Trans. Electr. Insul. 1979, 14, 127-135. [CrossRef]

24. Haga, K.; Fujiwara, Y.; Ebinuma, Y.; Sasaki, N.; Ogishima, M.; Aihara, M. Development of 22 kV very low-frequency, high-voltage generator and the characteristics of partial discharge in XLPE cables. In Proceedings of the Symposium on Electrical Insulating Materials, Tokyo, Japan, 26 September 1988; pp. 175-178.

25. Pepper, D.; Kalkner, W. PD-measurement on typical defects on XLPE-insulated cables at variable frequencies. In Proceedings of the International Symposium on High Voltage Engineering, London, UK, 23-27 August 1999; p. 5.313.

26. Muhr, M.; Woschitz, R. Partial discharge diagnostic. In Proceedings of the International Conference on Properties \& Applications Dielectric Materials, Xi'an, China, 21 June 2000; pp. 223-226.

27. Holbøll, J.T.; Edin, H. PD detection vs loss measurements at high voltages with variable power frequencies. In Proceedings of the International Symposium on High Voltage Engineering, Montreal, QC, Canada, 25-29 August 1997; pp. 4.421-4.425.

28. Giddens, J.; Edin, H.; Gäfvert, U. Measuring system for phase-resolved partial discharge detection at low frequencies. In Proceedings of the International Symposium on High Voltage Engineering, London, UK, 23-27 August 1999; pp. 5.228-5.231.

29. Edin, H.; Forssén, C. Variable frequency partial discharge analysis of in-service aged machine insulation. In Proceedings of the Nordic Insulation Symposium, Tampere, Finland, 11-13 June 2003; pp. 1-7.

30. Forssén, C.; Edin, H. Partial discharges in a cavity at variable applied frequency part 1: Measurements. IEEE Trans. Dielectr. Electr. Insul. 2008, 15, 1601-1609. [CrossRef]

31. Forssén, C.; Edin, H. Partial discharges in a cavity at variable applied frequency part 2: Measurements and modeling. IEEE Trans. Dielectr. Electr. Insul. 2008, 15, 1610-1616. [CrossRef]

32. Forssén, C. Modelling of Cavity Partial Discharges at Variable Applied Frequency. Ph.D. Thesis, Royal Institute of Technology, Stockholm, Sweden, 2008.

33. Taylor, N. Dielectric Response and Partial Discharge Measurements on Stator Insulation at Varied Low Frequency. Ph.D. Thesis, Royal Institute of Technology, Stockholm, Sweden, 2010.

34. Chimunda, S.; Chidzikwe, C.; Nyamupangedengu, C. A comparative study of surface partial discharge parameters at very low frequency (VLF) and power frequency test voltages. In Proceedings of the Southern African Universities Power Engineering Conference, Johannesburg, South Africa, 28-30 January 2015; pp. 255-260.

35. Zhou, Y.; Zhou, Z.; Zhang, L.; Zhang, Y.; Mo, Y.; Sun, J. Characterization and comprehension of corona partial discharge in air under power frequency to very low frequency voltage. Plasma Sci. Technol. 2018, 20, 1-9. [CrossRef]

36. Nguyen, H.V.P.; Phung, B.T.; Blackburn, T. Effect of temperatures on very low frequency partial discharge diagnostics. In Proceedings of the IEEE International Conference on Properties \& Applications of Dielectric Materials, Sydney, Australia, 19-22 June 2015; pp. 272-275.

37. Nguyen, H.V.P.; Phung, B.T.; Blackburn, T. Effects of ambient conditions on partial discharges at very low frequency (VLF) sinusoidal voltage excitation. In Proceedings of the IEEE Electrical Insulation Conference, Seattle, WA, USA, 7-10 June 2015; pp. 266-269.

38. Nguyen, H.V.P.; Phung, B.T.; Blackburn, T. Effects of aging on partial discharge patterns in voids under very low frequency excitation. In Proceedings of the IEEE International Conference Dielectrics, Montpellier, France, 3-7 July 2016 ; pp. 524-527.

39. Schurch, R.; Donoso, P.; Ardila-Rey, J.; Montana, J.; Angulo, A. Electrical tree growth under very low frequency (VLF) voltage excitation. In Proceedings of the IEEE Conference on Electrical Insulation and Dielectric Phenomena, Cancun, Mexico, 21-24 October 2018; pp. 338-341.

40. Fynes-Clinton, D.; Nyamupangedengu, C. Partial discharge characterization of cross-linked polyethylene medium voltage power cable termination defects at very low frequency $(0.1 \mathrm{~Hz})$ and power frequency test voltages. IEEE Electr. Insul. Mag. 2016, 32, 15-23. [CrossRef]

41. Nair, R.P.; Sumangala, B.V.; Rao, N.B. Identification of slot discharges in rotating machine insulation system using variable frequency PD measurement. IET High Volt. 2018, 3, 179-186. [CrossRef]

42. Eberg, E.; Aakre, T.G.; Berg, G.; Hvidsten, S. Comparison of offline VLF PD measurements and online PD measurements on a 50-year-old hydrogenerator stator in Norway. In Proceedings of the Electrical Insulation Conference, San Antonio, TX, USA, 17-20 June 2018; pp. 542-546.

43. Florkowska, B.; Zydron, P.; Florkowski, M. Analysis of PD phase-resolved images at low frequency of testing voltage. In Proceedings of the IEEE International Symposium on Electrical Insulation, Indianapolis, IN, USA, 19-22 September 2004; pp. 143-146.

44. Krüger, M. New very low frequency methods for testing extruded cables. In Proceedings of the IEEE International Symposium on Electrical Insulation, Toronto, ON, Canada, 3-6 June 1990; pp. 286-289.

45. Wolfgang, H. Critical review of voltages applied for quality-acceptance and diagnostic field tests on high-voltage and extra-highvoltage cable systems. IEEE Electr. Insul. Mag. 2013, 29, 16-25.

46. Hernández-Mejia, J.C.; Harley, R.; Hampton, N.; Hartlein, R. Characterization of ageing for MV power cables using low frequency $\tan \delta$ diagnostic measurements. IEEE Trans. Dielectr. Electr. Insul. 2009, 16, 862-870. [CrossRef]

47. Liu, Y.; Cao, X. Insulation performance evaluation of HV AC/DC XLPE cables by $0.1 \mathrm{~Hz}$ tan $\delta$ test on circumferentially peeled samples. IEEE Trans. Dielectr. Electr. Insul. 2017, 24, 3941-3950. [CrossRef] 
48. David, E.; Lamarre, L. Low-frequency dielectric response of epoxy-mica insulated generator bars during multi-stress aging. IEEE Trans. Dielectr. Electr. Insul. 2017, 14, 212-226. [CrossRef]

49. Hvidsten, S.; Ildstad, E.; Holmgren, B.; Werelius, P. Correlation between AC breakdown strength and low frequency dielectric loss of water tree aged XLPE cables. IEEE Trans. Power Deliv. 1998, 13, 40-45. [CrossRef]

50. Kuffel, E.; Zaengal, W.S.; Kuffel, J. High Voltage Engineering Fundamental, 2nd ed.; Elsevier: Great Britain, UK, 2000.

51. Hauschild, W.; Lemke, E. High-Voltage Test and Measuring Techniques, 2nd ed.; Springer: Berlin/Heidelberg, Germany, 2014.

52. Lemke, E. A critical review of partial-discharge models. IEEE Electr. Insul. Mag. 2012, 28, 11-16. [CrossRef]

53. Gärfert, U.; Edin, H.; Forssén, C. Modelling of partial discharge spectra measured with variable applied frequency. In Proceedings of the IEEE International Conference on Properties \& Applications of Dielectric Materials, Nagoya, Japan, 1-5 June 2003; pp. 839-842.

54. Okamoto, T.; Kato, T.; Yokomizu, Y.; Suzuoki, Y.; Tanaka, T. PD characteristics as a stochastic process and its integral equation under sinusoidal voltage. IEEE Trans. Dielectr. Electr. Insul. 2001, 8, 82-90. [CrossRef]

55. Suzuki, H.; Aihara, K.; Okamoto, T. Complex behaviour of a simple partial-discharge model. EPL (Europhys. Lett.) 2004, 66, 28-34. [CrossRef]

56. Agoris, D.P.; Hatziargyriou, N.D. Approach to partial discharge development in closely coupled cavities embedded in solid dielectrics by the lumped capacitance model. IEE Proc. Sci. Meas. Technol. 1993, 140, 131-134. [CrossRef]

57. Chia, P.Y.; Liew, A.C. Novel approach to partial discharge signals modeling in dielectric insulation void using extension of lumped capacitance model. In Proceedings of the International Conference on Power System Technology (PowerCon), Perth, WA, Australia, 4-7 December 2000; pp. 1207-1212.

58. Samat, S.S.; Musirin, I.; Kusim, A.S. The effect of supply voltage on partial discharge properties in solid dielectric. In Proceedings of the IEEE International Power Engineering and Optimization Conference, Melaka, Malaysia, 6-7 June 2012; pp. $490-495$.

59. Negm, T.S.; Refaey, M.; Hossam-Eldin, A.A. Modeling and simulation of internal Partial Discharges in solid dielectrics under variable applied frequencies. In Proceedings of the IEEE International Middle East Power Systems Conference, Cairo, Egypt, 27-29 December 2016; pp. 1-6.

60. Pedersen, A. Current pulses generated by discharges in voids in solid dielectrics. A field theoretical approach. In Proceedings of the IEEE International Symposium on Electrical Insulation, Washington, DC, USA, 8-11 June 1986; p. 112.

61. Pedersen, A. Partial discharges in voids in solid dielectrics, an alternative approach. In Proceedings of the IEEE Conference on Electrical Insulation and Dielectric Phenomena, Gaithersburg, MD, USA; 1987; pp. 58-64.

62. Niemeyer, L. A generalized approach to partial discharge modeling. IEEE Trans. Dielect. Electr. Insul. 1995, 2, 510-528. [CrossRef]

63. Gutfleisch, F.; Niemeyer, L. Measurement and simulation of PD in epoxy voids. IEEE Trans. Dielect. Electr. Insul. 1995, 2, 729-743. [CrossRef]

64. Bodega, R.; Cavallini, A.; Morshuis, P.H.F.; Wester, F.J. The effect of voltage frequency on partial discharge activity. In Proceedings of the IEEE Conference on Electrical Insulation and Dielectric Phenomena, Cancun, Mexico, 20-24 October 2002; pp. 685-689.

65. Forssén, C.; Edin, H. Field model of partial discharges at variable frequency of the applied voltage. In Proceedings of the Nordic Insulation Symposium, Trondheim, Norway, 13-15 June 2005; pp. 121-124.

66. Forssén, C.; Edin, H. Modeling partial discharges in a cavity at different applied frequencies. In Proceedings of the IEEE Conference on Electrical Insulation and Dielectric Phenomena, Vancouver, BC, Canada, 14-17 October 2007; pp. $132-135$.

67. Chen, G.; Baharudin, F. Partial discharge modelling based on a cylindrical model in solid dielectrics. In Proceedings of the International Conference on Condition Monitoring and Diagnosis, Beijing, China, 21-24 April 2008; pp. 74-78.

68. Baharudin, F. Modeling Partial Discharges in a Solid Dielectric Material's Cavity using COMSOL and MATLAB Software. MEng Thesis, University of Southampton, Southampton, UK, 2007.

69. Nguyen, H.V.P.; Phung, B.T.; Morsalin, S. Modelling partial discharges in an insulation material at very low frequency. In Proceedings of the International Conference on High Voltage Engineering and Power System, Sanur, Indonesia, 2-5 October 2017; pp. 451-454.

70. Illias, H.A.; Chen, G.; Lewin, P.L. Partial discharge behavior within a spherical cavity in a solid dielectric material as a function of frequency and amplitude of the applied voltage. IEEE Trans. Dielectr. Electr. Insul. 2011, 18, 432-443. [CrossRef]

71. Illias, H.A. Measurement and Simulation of Partial Discharges within a Spherical Cavity in a Solid Dielectric Material. Ph.D. Thesis, University of Southampton, Southampton, UK, 2011.

72. Feng, X.; Xiong, Q.; Gattozzi, A.; Montanari, G.C.; Seri, P.; Hebner, R. Cable commissioning and diagnostic tests: The effect of voltage supply frequency on partial discharge behavior. In Proceedings of the IEEE International Conference on Properties and Applications of Dielectric Materials, Xi'an, China, 20-24 May 2018; pp. 373-376.

73. Cavallini, A.; Krotov, V.; Montanari, G.C.; Morshuis, P.H.F.; Mariut, L.E. The role of supply frequency in the evaluation of partial discharge inception voltage in XLPE-embedded cavities. In Proceedings of the IEEE Conference on Electrical Insulation and Dielectric Phenomena, Montreal, QC, Canada, 14-17 October 2012; pp. 487-490.

74. Cavallini, A.; Montanari, G.C.; Hauschild, W. Discussion on: Effect of supply voltage frequency on testing of insulation system. IEEE Trans. Dielectr. Electr. Insul. 2006, 13, 1189-1191. [CrossRef]

75. Probst, R.; Putter, H.; Petzold, F.; Legler, P. Excitation voltages for partial discharge diagnostics on medium voltage distribution cables. In Proceedings of the IEEE/PES Transmission and Distribution Conference and Exposition, Denver, CO, USA, 18-21 September 2018. 
76. Pepper, D.; Kalkner, W. PD-pattern of defects in XLPE cable insulation at different test voltage shapes. In Proceedings of the International Symposium on High Voltage Engineering, London, UK, 23-27 August 1999; pp. 313-316.

77. Salathe, D. New methods for offline PD diagnosis on MV cable systems. In Proceedings of the International Power System Conference, Tehran, Iran, 23-25 November 2015; pp. 374-379.

78. Gouda, O.; ElFaraskoury, A.; ElSinary, A.; Farag, A. Investigating the effect of frequency and wave shape of voltage source on partial discharge behaviour within cavity in medium voltage cable. In Proceedings of the International Middle East Power Systems Conference, Cairo, Egypt, 19-21 December 2017; pp. 1093-1099.

79. Hou, Z.; Li, H.; Chen, S.; Li, B.; Lu, Y.; Ji, S. Development of a novel $20 \mathrm{kV} 0.1 \mathrm{~Hz}$ very low frequency cosine-rectangular voltage generator for insulation testing of power cables. IET Gener. Transm. Distrib. 2018, 12, 1-8. [CrossRef]

80. Xie, C.; Wang, Y.; Shao, X.; Jin, Y. The application research of very low frequency diagnostic methods in acceptance tests on new cable systems of medium voltage. In Proceedings of the China International Conference on Electricity Distribution, Tianjin, China, 17-19 September 2018; pp. 47-53.

81. Putter, H.T.; Götz, D.; Petzold, F.; Oetjen, H. The evolution of VLF testing technologies over the past two decades. In Proceedings of the IEEE/PES Transmission and Distribution Conference and Exposition, Orlando, FL, USA, 7-10 May 2012.

82. Auclair, H.; Boone, W.; Papadopulos, M.S. Development of a new after laying test method for high voltage power cable systems. In Proceedings of the CIGRE Symposium, Paris, France, 28 August-3 September 1988. Paper 21-06.

83. Koevoets, R.C.A.M. A new after laying dielectric test for underground HV extruded cables. In Proceedings of the IEEE International Symposium on Electrical Insulation, Toronto, ON, Canada, 3-6 June 1990; pp. 313-320.

84. Lemke, E.; Roding, R.; Weisenberg, W. On-site testing of extruded power cables by PD measurement at switching impulse voltages. In Proceedings of the CIGRE Symposium, Gaithersburg, MD, USA; 1987; p. 1020-02.

85. Aucourt, C.; Louis, M. After laying tests of accessories of synthetic insulated cable with oscillating wave. In Proceedings of the International Symposium on High Voltage Engineering, New Orleans, LA, USA, 28 August-1 September $1989 ;$ p. 47.

86. Aucourt, C.; Boone, W.; Kalkner, W.; Naubour, R.D.; Ombello, F. Recommendation for a new after laying test method for high voltage extruded cable systems. In Proceedings of the International Council on Large Electric Systems, 26 August 1990.

87. IEEE Guide for Field Testing of Shielded Power Cable Systems Rated $5 \mathrm{kV}$ and above with Damped Alternating Current (DAC) Voltage;

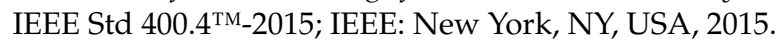

88. High-Voltage Test Techniques-Partial Discharge Measurements; IEC Standard 60270: 2000/A1: 2015; IDT: Geneva, Switzerland, 2016.

89. Uchida, K.; Tanaka, H.; Hirotsu, K. Study on detection for the defects of XLPE cable lines. IEEE Trans. Power Deliv. 1996, 11, 663-668. [CrossRef]

90. Lemke, E.; Schmiegel, P. Complex Discharge Analyzing (CDA)-an alternative procedure for diagnosis tests of HV power apparatus of extremely high capacity. In Proceedings of the International Symposium on High Voltage Engineering, Graz, Austria, 28 August-1 September 1995; p. 5617.

91. Lemke, E.; Schmiegel, P.; Elze, H.; Russwurm, D. Procedure for evaluation of dielectric properties based on complex discharge analyzing (CDA). In Proceedings of the IEEE International Symposium on Electrical Insulation, Montreal, QC, Canada, 16-19 June 1996; pp. 385-388.

92. Brettschneider, S.; Lemke, E.; Hinkle, J.L.; Schneider, M. Recent field experience in PD assessment of power cables using oscillating voltage waveforms. In Proceedings of the IEEE International Symposium on Electrical Insulation, Montreal, QC, Canada, 16-19 June 1996; pp. 546-552.

93. Gulski, E.; Smit, J.J.; Seitz, P.N.; Smit, J.C. PD measurements on-site using oscillating wave test system. In Proceedings of the IEEE International Symposium on Electrical Insulation, Arlington, VA, USA, 7-10 June 1998; pp. 420-423.

94. Gulski, E.; Smit, J.J.; Seitz, P.N.; Smit, J.C.; Turner, M. On-site PD diagnostics of power cables using oscillating wave test system. In Proceedings of the International Symposium on High Voltage Engineering, London, UK,, 23-27 August 1999; pp. 112-115.

95. Gulski, E.; Wester, F.J.; Smit, J.J.; Seitz, P.N.; Turner, M. Advanced partial discharge diagnostic of MV power cable system using oscillating wave test system. IEEE Electr. Insul. Mag. 2000, 16, 17-25. [CrossRef]

96. Gulski, E.; Rakowska, A.; Siodła, K.; Jongen, R.; Minassian, R.; Cichecki, P.; Parciak, J.; Smit, J.J. On-site testing and diagnosis of transmission power cables up to $230 \mathrm{kV}$ using damped AC voltages. IEEE Electr. Insul. Mag. 2014, 30, 27-38. [CrossRef]

97. Gulski, E.; Wester, F.J.; Wester, P.; Groot, E.R.S.; van Doeland, J.W. Condition assessment of high voltage power cables. In Proceedings of the International Conference on Large Electric Systems, Singapore, 21-24 November 2004.

98. Seitz, P.P.; Quak, B.; Gulski, E.; Smit, J.J.; Cichecki, P.; de Vries, F.; Petzold, F. Novel method for on-site testing and diagnosis of transmission cables up to 250kV. Jicable '07. In Proceedings of the 7th International Conference on Insulated Power Cables, Paris, France, 24-28 June 2007; p. 16.

99. Houtepen, R.; Chmura, L.; Smit, J.J.; Quak, B.; Seitz, P.P.; Gulski, E. Estimation of dielectric loss using damped AC voltages. IEEE Electr. Insul. Mag. 2011, 27, 14-19. [CrossRef]

100. Wester, F. Condition Assessment of Power Cables Using Partial Discharge Diagnosis at Damped AC Voltages. Ph.D. Thesis, Delft University of Technology, Delft, The Netherlands, 2004.

101. Plath, R. Oscillating Voltages als Prüfspannung zur Vor-Ort-Prüfung und TE-Messung Kunststoffisolierter Kabel; Verlag Dr. Köster: Berlin, Germany, 1994.

102. Quak, B.; Petzold, F.; Lemke, E.; Jongen, R.; Cichecki, P. International Survey of Using Damped AC Voltages for Testing MV and E(HV) Power Cables; PES ICC.; Spring: Pittsburgh, PA, USA, 2013. 
103. Gulski, E.; van Breen, H.J.; Smit, J.J.; Seitz, P.N.; Schikarski, P. Partial discharge detection in generator stator insulation using oscillating voltage waves. In Proceedings of the Electrical Insulation Conference and Electrical Manufacturing \& Coil Winding Conference, Cincinnati, OH, USA, 16-18 October 2001; pp. 331-334.

104. Eeden, C.J.V. Measurement of Partial Discharges and Dielectric Losses on Rotating Machines Using Damped AC Voltages. Master's Thesis, Delft University of Technology, Delft, The Netherlands, 2010.

105. Gulski, E.; Meijer, S.; van Breen, H.J.; Seitz, P.P.; de Vries, F.; Petzold, F. Partial discharge diagnosis of stator insulation using damped AC voltages. In Proceedings of the IEEE International Symposium on Electrical Insulation, Toronto, ON, Canada, 11-14 June 2006; pp. 6-9.

106. Kuraishi, T.; Miyazaki, S.; Takahashi, T.; Takahashi, T.; Kato, O.; Hayashi, Y. Applicability of oscillating wave test system for on-site PD diagnosis of high voltage power capacitors. In Proceedings of the International Symposium on Electrical Insulating Materials, Niigata, Japan; 2014; pp. 172-175.

107. Setyawan, J. Investigation of Partial Discharge Occurrence and Detectability in High Voltage Power Cable Accessories. Master's Thesis, Delft University of Technology, Delft, The Netherlands, 2009.

108. Wester, F.J.; Gulski, E.; Smith, J.J. Detection of partial discharges at different AC voltage stresses in power cables. IEEE Electr. Insul. Mag. 2007, 23, 28-43. [CrossRef]

109. Gulski, E.; Cichecki, P.; Wester, F.; Smit, J.J.; Bodega, R.; Hermans, T.J.W.H. On-site testing and PD diagnosis of high voltage power cables. IEEE Trans. Dielectr. Electr. Insul. 2008, 15, 1691-1700. [CrossRef]

110. Cichecki, P. Testing and Diagnosis of High Voltage and Extra High Voltage Power Cables with Damped AC Voltages. Ph.D. Thesis, Delft University of Technology, Delft, The Netherlands, 2018.

111. Takahashi, T.; Takahashi, T.; Okamoto, T. Study on insulation diagnosis for XLPE cables using dumping oscillating high voltage. In Proceedings of the International Conference on Condition Monitoring and Diagnosis, Beijing, China, 21-24 April 2008; pp. 471-474.

112. Takahashi, T.; Takahashi, T.; Okamoto, T. Influence of repetitive application of damped AC voltage on insulation performance of water tree aged XLPE cable. In Proceedings of the IEEE Conference on Electrical Insulation and Dielectric Phenomena, Virginia Beach, VA, USA, 18-21 October 2009; pp. 299-302.

113. Zhou, Z.; Xu, P.; Li, H.; Ji, S.; Zhang, W.; Zhou, H.; Xu, F. Development of a $20 \mathrm{kV}$ damped oscillating voltage generator. IET Power Electron. 2016, 9, 680-688.

114. Li, G.; Luo, Z.; Xiong, J.; Huang, Z.; Wang, Y. Statistical characteristics of partial discharge caused by typical defects in cable joint under oscillating voltage. In Proceedings of the International Conference on Power System Technology, Chengdu, China, 20-22 October 2014; pp. 1368-1373.

115. Lu, G.; Wu, G.; Xiong, J.; Liu, Y. Sensitivity analysis of cable oscillating wave test system on multi-source defects diagnostics. CIRED. Open Access Proc. J. 2017, 2017, 424-427. [CrossRef]

116. Xiong, J.; Wang, Y.; Mo, W.; Fan, W.; Lei, C.; Jiang, Y.; Zhang, H.; Ma, G. Comparative investigations on XLPE cables with using damped-Ac and 50-Hz-Ac. In Proceedings of the IEEE International Conference on Dielectrics, Budapest, Hungary, 1-5 July 2018.

117. Morshuis, P.H.F.; Bodega, R.; Lazzaroni, M.; Wester, F.J. Partial discharge detection using oscillating voltage at different frequencies. In Proceedings of the IEEE Instrumentation \& Measurement Technology Conference, Anchorage, AK, USA, 21-23 May 2002; pp. 431-435.

118. Su, C.Q.; Li, C.R. Using very-low-frequency and oscillating-wave tests to improve the reliability of distribution cables. IEEE Electr. Insul. Mag. 2013, 29, 38-45. [CrossRef] 